\title{
TRAPPC9: Novel insights into its trafficking and signaling pathways in health and disease (Review)
}

\author{
THOMAS MBIMBA ${ }^{1-3^{*}}$, NAZAR J. HUSSEIN ${ }^{1-3^{*}}$, AYESHA NAJEED $^{1,2}$ and FAYEZ F. SAFADI ${ }^{1-5}$ \\ ${ }^{1}$ Department of Anatomy and Neurobiology, College of Medicine; ${ }^{2}$ Musculoskeletal Research Group, \\ Northeast Ohio Medical University, Rootstown, OH 44272; ${ }^{3}$ School of Biomedical Sciences, Kent State University, \\ Kent, OH 44240; ${ }^{4}$ Rebecca D. Considine Research Institute, Akron Children's Hospital, Akron, OH 44308; \\ ${ }^{5}$ Department of Orthopedic Surgery, SUMMA Health System, Akron, OH 44304, USA
}

Received May 2, 2018; Accepted August 14, 2018

DOI: $10.3892 /$ ijmm.2018.3889

\begin{abstract}
Trafficking protein particle complex 9 (TRAPPC9) is a protein subunit of the transport protein particle II (TRAPPII), which has been reported to be important in the trafficking of cargo from the endoplasmic reticulum (ER) to the Golgi, and in intra-Golgi and endosome-to-Golgi transport in yeast cells. In mammalian cells, TRAPPII has been shown to be important in Golgi vesicle tethering and intra-Golgi transport. TRAPPC9 is considered to be a novel molecule capable of modulating the activation of nuclear factor $-\kappa \mathrm{B}(\mathrm{NF}-\kappa \mathrm{B})$. Mutations in TRAPPC9 have been linked to a rare consanguineous hereditary form of mental retardation, as part of the $\mathrm{NF}-\kappa \mathrm{B}$ pathways. In addition, TRAPPC9 has been reported to be involved in breast and colon cancer and liver diseases. The present review highlights the most recent publications on the structure, expression and function of TRAPPC9, and its association with various human diseases.
\end{abstract}

\section{Contents}

1. Introduction

2. Structure

3. Expression

4. Function

5. Trafficking

Correspondence to: Professor Fayez F. Safadi, Department of Anatomy and Neurobiology, College of Medicine, Northeast Ohio Medical University, 4209 State Route 44, Rootstown, OH 44272, USA

E-mail: fayez.safadi@neomed.edu

*Contributed equally

Key words: transport protein particle II, trafficking protein particle complex 9, nuclear factor- $\kappa \mathrm{B}$; nuclear factor- $\kappa \mathrm{B}$-inducing kinase; inhibitor of nuclear factor $-\kappa \mathrm{B}$ kinase subunit $\beta$, protein trafficking, cancer, cell signaling
6. $N F-\kappa B$

7. TRAPPC9 in human diseases

8. Concluding remarks

\section{Introduction}

Trafficking protein particle complex subunit 9 (TRAPPC9) is a protein subunit of the transport protein particle II (TRAPPII), a conserved trafficking molecule in organisms ranging from yeast to humans (1). TRAPPII shares similarity with complexes TRAPPI and TRAPPIII, in that all three complexes comprise six core proteins. However, TRAPPII is the only complex that contains TRAPPC9 in addition to two other TRAPPII-specific proteins (TRAPPC10 and TRAPPC2L) (2). The TRAPPII complex is a Rab1 guanine exchange factor known to bind coat protein I (COPI) and to serve as a tethering complex for COPI-coated vesicles to the early Golgi membrane. During TRAPPII complex formation, TRAPPC9 has been shown to interact with TRAPPC2 and TRAPPC10. In addition, TRAPPC9 has been reported to bind and interact with p150(Glued) at the trans-Golgi region (3). Studies have also suggested that mutations in TRAPPC9 are linked with a form of mental retardation (MR) associated with severe osseous deformities, including short stature and polydactylism (4). Clinical phenotypes associated with TRAPPC9 mutation have been linked with decreased activation of nuclear factor $-\kappa \mathrm{B}(\mathrm{NF}-\kappa \mathrm{B})$. NF- $\kappa \mathrm{B}$ is critical in the activation of genes associated with multiple pathways (5). In the present review, the possible roles and functions of TRAPPC9 in normal and disease processes are highlighted.

\section{Structure}

A survey of the human proteome by Schou et al (6) identified two protein domains in TRAPPC9: An ASPM, $\underline{\text { SPD-2, }}$ Hydin (ASH) domain at the C-terminal, and predicted $\alpha$-solenoid-bearing stretches of multiple tetratricopeptide (TPR) repeats (Fig. 1). The TPR repeats have been identified in numerous proteins and may serve as binding elements in multiprotein complexes (7). The TPR repeats are also considered to regulate diverse biological processes, including organelle targeting and protein import, vesicle fusion and 
biomineralization (7-9). By contrast, the ASH domain is typically present in proteins associated with cilia, flagella, the centrosome and the Golgi complex (10).

\section{Expression}

In humans, TRAPPC9 (MIM no. 611966) is encoded by the gene located at locus $8 \mathrm{q} 24.3$ and contains 23 exons. TRAPPC9 is a conserved protein with sequence similarity of the human gene found in mouse (92\%), chicken (87\%) and zebrafish (85\%) (9). TRAPPC9 has a conserved region (Trs120), first identified in Saccharomyces cerevisiae $(12,13)$. Two variants have been identified in humans, one encoding a 1,148-amino acid protein and the second encoding a 1,246-amino acid protein. Compared to the human form, the mouse TRAPPC9 gene is located on 15_NC_000081.6 and five variants have been identified; the first variant encodes a 3,324-amino acid protein (NM_029640.2), the second encodes a 4,069-amino acid protein (NM_180662.2), the third encodes a 4,688-amino acid protein (NM_001164641.1), the fourth encodes a 3,127 amino acid protein (NM_001164642.1) and the fifth encodes a 2,833-amino acid protein (NM_001164643.1). TRAPPC9 is expressed at high levels in the developing cortical plate of the human embryonic brain (at 11.5 weeks gestation) and in the mouse brain during its adult phase according to in situ hybridization data (13). In mice, the expression of TRAPPC9 has been localized in neurons of the cerebral cortex, the hippocampus and deep gray matter (13). Another study revealed that TRAPPC9 may also be expressed in mouse colon and small intestine tissues by conventional reverse transcription-polymerase chain reaction analysis (11). Further analysis of human tissues by Zhang et al (11) using northern blot analysis indicated a high expression of TRAPPC9 in muscle and the kidneys, and low expression in the brain, heart and placenta. TRAPPC 9 was also shown to be weakly expressed in immune organs and cells, including the thymus, spleen and peripheral blood leukocytes.

\section{Function}

TRAPPC9 is part of the TRAPPII complex, which is important in intra-Golgi and endosomal trafficking in yeast $(14,16)$. In mammals, TRAPPC9 is predominantly expressed at the endoplasmic reticulum (ER) exit sites (17). All TRAPP complexes share six core subunits, namely trafficking protein particle complex subunits 20, 23, 31 and 33 (Trs20, 23, 31 and 33 , respectively) and two copies of Bet3, in addition to Bet5 and the six core proteins. TRAPPII also contains four specific proteins, Trs65, Trs120 (TRAPPC9), Trs130 (TRAPPC10) and Tcal17, specific to TRAPPII $(18,20)$. TRAPPC9 has been shown to be involved in the NF- $\mathrm{KB}$ signaling pathway by physically interacting and regulating NF- $\kappa \mathrm{B}$-inducing kinase (NIK)

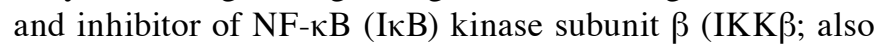
known as IKK2) activation (21). A previous study indicated that TRAPPC9 may regulate enteric neuronal differentiation through the NF- $\mathrm{kB}$ signaling pathway (11).

\section{Trafficking}

Newly synthesized proteins must be transported from the ER to the Golgi complex via the secretory pathway (22). To

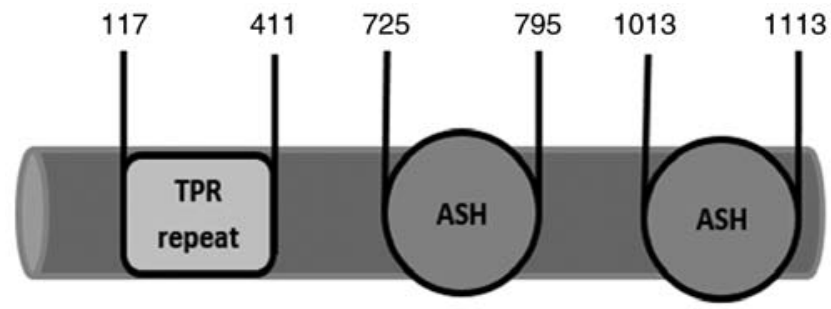

Figure 1. TRAPPC9 structure. The domain architecture of TRAPPC9 protein exhibits ASH domains, identified by reciprocal HHpred searches, and TPR repeat regions, identified by HHpred and TPRpred. Adapted from Ref (4) TRAPPC9, trafficking protein particle complex 9; ASH, ASPM, SPD-2, Hydin; TPR, tetratricopeptide.

ensure the directionality and accuracy of the protein transport process, the process is completed and regulated by intracellular membrane traffic complexes. In yeast and mammals, several of the mechanisms that have been suggested to underlie the secretory pathways within cells have been indicated through decades of research (23).

TRAPPC9 is part of the TRAPPII complex, which is expressed predominantly at the ER exit sites in mammals and has been suggested to function in intra-Golgi and endosome-to-Golgi transport (17) (Fig. 2). TRAPPC9 interacts with the TRAPPC10 subunit of TRAPPII, which is considered to function as a guanine exchange factor for Ypt/Rab GTPase by activating Rab1 (24). Site-directed mutagenesis of TRAPPC10 has indicated that it may be implicated in autophagy, and may be important in cytoplasmic-to-vacuole targeting and starving-induced autophagy in Saccharomyces cerevisiae (24). Compared to TRAPPC10, mutation in TRAPPC9 reportedly causes the accumulation of aberrant membrane structures that resemble Berkeley bodies, which is the transport medium between the cytoplasm and vacuole within the cytoplasm-to-vacuole targeting pathway in yeast; this results in disruption to the trafficking of proteins that recycle through the early endosome (15). TRAPPII is enriched on coat protein I (COPI)-coated vesicles and interacts directly with $\gamma 1 \mathrm{COP}$, a COPI coat adaptor subunit and the heptameric complex that forms the coat of COPI vesicles (23-25). Zong et al (3) demonstrated that TRAPPC9 may bind and interact with p150(Glued) at the same carboxyl terminal domain of p150(Glued) that binds Sec23 and Sec24. TRAPPC9 has also been shown to co-localize with the late Golgi marker Sec7p (15). Previous site-directed mutagenesis of TRAPPC9 resulted in defects in the localization of COPI. Furthermore, it had been suggested that TRAPPC9 may serve to uncouple p150(Glued) from the COPII coat and to relay the vesicle-dynactin interaction at the target membrane (3). The functions associated with TRAPPC9 are summarized in Table I $(3,11,15,21,40-42)$.

\section{NF-кB}

The NF- $\kappa \mathrm{B}$ family comprises structurally related transcription factors that regulate various biological processes, including stress responses, immunity and inflammation (28). The activation of NF- $\mathrm{KB}$ is mediated by 'canonical' and 'non-canonical' pathways (29). The canonical pathway is activated by multiple stimuli, including receptor activator of NF- $\mathrm{kB}$ ligand (RANKL), 

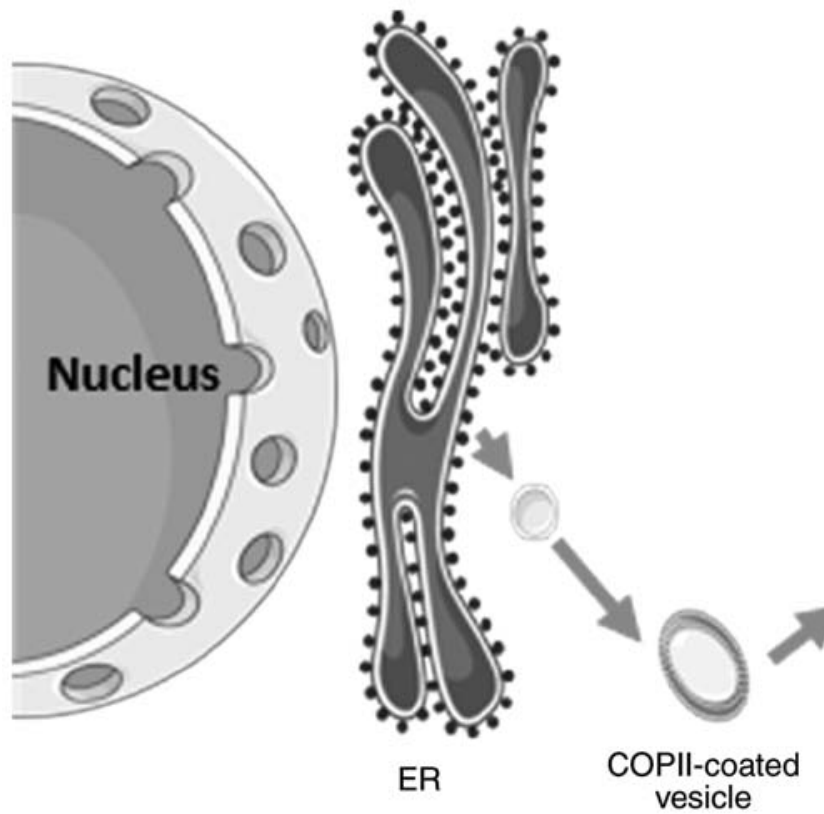

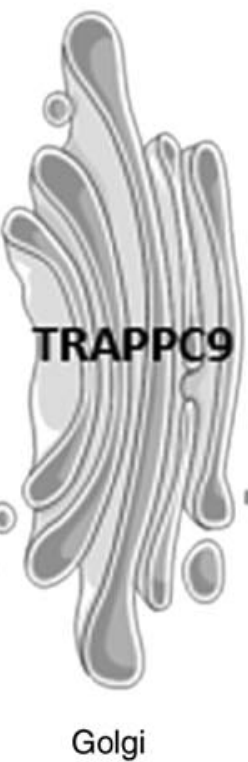

Golgi

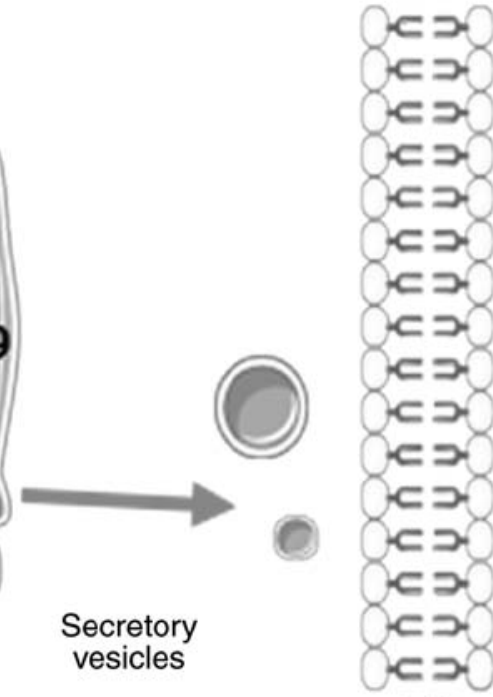

Cell membrane

Figure 2. Role of TRAPPC9 in intra-Golgi vesicle trafficking. COPII-coated vesicles mediate vesicle trafficking from the ER to the Golgi, which interacts with the TRAPPI complex. TRAPPII also mediates vesicle tethering to the Golgi and intra-Golgi. TRAPPC9 is a specific subunit of the TRAPPII complex, therefore, TRAPPC9 mainly interacts with Golgi proteins. TRAPPC9, trafficking protein particle complex 9; TRAPPI/II, transport protein particle I/II; COPII, coat protein II; ER, endoplasmic reticulum.

tumor necrosis factor (TNF)- $\alpha$ and other inflammatory mediators (30). In turn, this pathway is mediated by activation of the IKK complex, which regulates phosphorylation and proteolysis of the I $\kappa \mathrm{B} \alpha$ inhibitors and consequent nuclear translocation of the RelA and p50 transcriptional activators (30). By contrast, the non-canonical NF- $\kappa \mathrm{B}$ activation pathway involves the activation of NIK to stimulate IKK $\alpha$-induced phosphorylation, the proteolytic processing of $\mathrm{NF}-\kappa \mathrm{B} 2$ into $\mathrm{p} 52$, and the nuclear translocation of RelB (31). The most well-characterized non-canonical NF- $\mathrm{NB}$ signaling is a subset of TNF receptor superfamily members, including B-cell-activating factor belonging to the TNF family receptor, cluster of differentiation 40 and lymphotoxin $\beta$-receptor (32). TRAPPC9 has been shown to physically interact with NIK and IKK $\beta$, but not IKK $\alpha$ or IKK $\gamma$ (21). Therefore, TRAPPC9 is implicated in the canonical and non-canonical NF- $\mathrm{NB}$ activation pathways (Fig. 3). Of note, TRAPPC 9 may potentiate the activation of $\mathrm{NF}-\kappa \mathrm{B}$ through increased phosphorylation of the IKK complex (21).

\section{TRAPPC9 in human diseases}

Central nervous system. Mutations in TRAPPC9 have been identified in patients with non-syndromic autosomal recessive MR (NS-ARMR) (5). One such mutation was identified in consanguineous family members and resulted in TRAPPC9 truncation; c.1422C $>$ T. Mutation has also been identified in three consanguineous Israeli-Arab female adolescents and in a large consanguineous Pakistani family, where it was caused by the nonsense mutation $\mathrm{R} 475 \mathrm{X}$ in exon $7(13,19)$. In addition, the novel homozygous nonsense mutation c.2065G>T in exon 11 of the TRAPPC9 gene was identified in a Pakistani family genome by whole exome sequencing (33). Another mutation resulting in a frameshift and premature truncation (p.Leu772TrpfsX7) is caused by a homozygous 4-bp deletion, c.2311-2314 delTGTT, identified in an Iranian family (34). A homozygous nonsense mutation resulting in p.Arg570Ter ( $\mathrm{R} 570 \mathrm{X}$ ) due to $\mathrm{c} .1708 \mathrm{C}>\mathrm{T}$ transcription has been identified in three Tunisian brothers from a consanguineous family (35). All patients with NS-ARMR exhibit a similar clinical MR phenotype ranging from moderate to severe. The clinical phenotype of patients with mutation in the TRAPPC9 gene is moderate to severe MR, including variable postnatal microcephaly. Mild facial dysmorphism and truncal obesity have also been reported in Tunisian brothers, whereas no facial dysmorphism has been observed in Pakistani, Israeli-Arab or Iranian patients $(13,5,35)$. Phenotypes associated with TRAPPC9 mutations have been consistently associated with postnatal microcephaly, speech delay, neuroradiological abnormality of the cerebral white matter, corpus callosum and cerebellum, peculiar facial appearance, obesity and hypotonia $(36,37)$. Magnetic resonance imaging in affected individuals has revealed reduced cerebral white matter volume with sulcal enlargement, thinning of the corpus callosum and mild cerebellar volume loss. These phenotypes have been linked with the downregulated activation of $N F-\kappa B$, and it is possible that the trafficking function of TRAPPC9 may also be affected. Human mutations associated with TRAPPC9 have been summarized in Table II $(13,33,37,36)$.

Liver disease. A previous study indicated that certain genetic loci are associated with features of histological severity in nonalcoholic fatty liver disease in a cohort of Hispanic boys (38). In this study, 234 Hispanic boys (aged 2-17 years) with available clinical, laboratory and histological data enrolled in the Nonalcoholic Steatohepatitis Clinical Research Network were included in the analysis of 624,297 single nucleotide polymorphisms (SNPs). The median age and body mass index z-score were 12.0 years [interquartile range (IQR), 
Table I. Summary of functions associated with TRAPPC9.

\begin{tabular}{|c|c|c|c|c|}
\hline Author, date & Organism & Designation & Function & (Refs.) \\
\hline Zong et al, 2012 & COS cells & TRAPPC9 & $\begin{array}{l}\text { TRAPPC9 bound directly to p } 150 \text { (Glued) via the same carboxyl } \\
\text { terminal domain of p } 150 \text { (Glued) that binds Sec } 23 \text { and Sec } 24 \text {. } \\
\text { TRAPPC9 reported to uncouple p } 150 \text { (Glued) from the COPII } \\
\text { coat and relay the vesicle-dynactin interaction at the target } \\
\text { membrane. TRAPPC9 inhibits the interaction between } \\
\text { p150 (Glued) and Sec } 23 / \mathrm{Sec} 24 \text { in vivo and in vitro. }\end{array}$ & (3) \\
\hline Zhang et al, 2014 & Bovine & NIBP & $\begin{array}{l}\text { Expression of TRAPPC } 9 \text { is high in the mouse enteric nervous } \\
\text { system. }\end{array}$ & (11) \\
\hline Cai et al, 2005 & Yeast & $\operatorname{Trs} 120$ & $\begin{array}{l}\text { TRAPPC9 is required for vesicle trafficking from early endosome } \\
\text { to late Golgi. TRAPPC9 co-localizes with the late Golgi marker } \\
\text { Sec7p. TRAPPC9 mutation causes accumulation of aberrant } \\
\text { membrane structures that resemble Saccharomyces cerevisiae } \\
\text { organelle Berkeley bodies and disrupt the traffic of proteins that } \\
\text { recycle through the early endosome. }\end{array}$ & (15) \\
\hline Hu et al, 2005 & PC12 cells & NIBP & 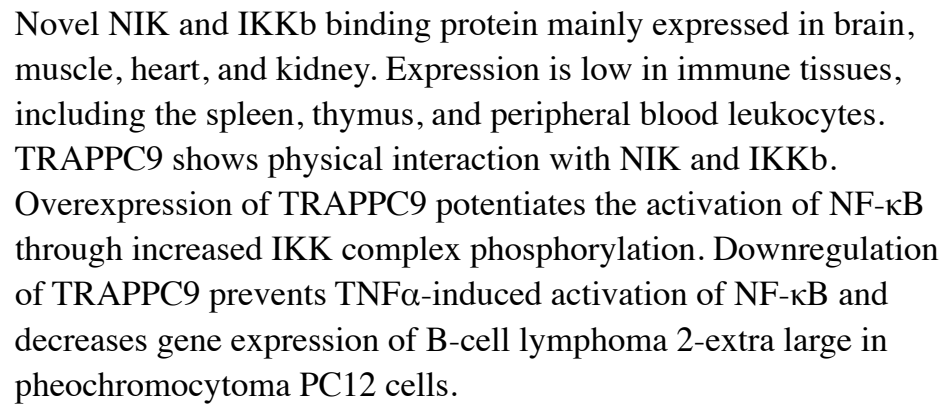 & $(21)$ \\
\hline Li et al, 2017 & $293 T$ cells & TRAPPC9 & $\begin{array}{l}\text { Regulates lipid droplet size and the association of Rab18 on the } \\
\text { lipid droplet surface. }\end{array}$ & $(40)$ \\
\hline Salamat et al, 2011 & Bovine & NIBP & $\begin{array}{l}\text { TRAPPC9 interacts with the } \mathrm{N} \text { terminus of the bovine viral } \\
\text { diarrhea virus NS5A. NS5A co-localizes with TRAPPC9 on the } \\
\text { endoplasmic reticulum in the cytoplasm of infected cells. }\end{array}$ & (41) \\
\hline $\begin{array}{l}\text { Thellmann et al, } \\
2010\end{array}$ & Arabidopsis & AtTRS120 & $\begin{array}{l}\text { TRAPPC9 is required for cell plate biogenesis. Mutations in } \\
\text { TRAPPC9 show canonical cytokinesis-defective seedling-lethal } \\
\text { phenotypes, including cell wall stubs and incomplete cross walls. } \\
\text { TRAPPC9 mutants show vesicle accumulation at the equator of } \\
\text { diving cells fails to assemble into a cell plate. }\end{array}$ & $(42)$ \\
\hline
\end{tabular}

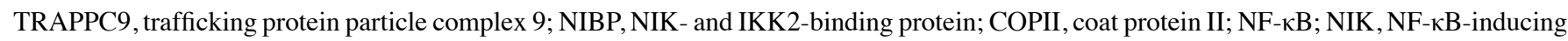
kinase; IKK $\beta$, inhibitor of NF- $\mathrm{BB}$ kinase subunit $\beta$; TNF $\alpha$, tumor necrosis factor- $\alpha$; NS5A, no-structural protein 5A.

11.0-14.0] and 2.4 (IQR, 2.1-2.6), respectively. Notably, the nonalcoholic fatty liver disease activity score (1-4, vs. 5-8) was associated with SNP rs11166927 on chromosome 8 in the TRAPPC9 region ( $\mathrm{P}=8.7-07)$ (38).

Breast/colon cancer. Zhang et al (39) investigated the potential regulatory mechanisms underlying the constitutive and inducible activation of NF- $\kappa \mathrm{B}$ in cancer as they remain to be fully elucidated. The study investigated whether a novel NIK- and IKK2-binding protein (NIBP/TRAPPC9) is required for maintaining the malignancy of cancer cells in an NF- $\kappa \mathrm{B}$-dependent manner by polymerase chain reaction analysis of a human cancer survey tissue-scan cDNA array, immunostaining of a human frozen tumor tissue array and immunoblotting of a high-density reverse-phase cancer protein lysate array. The study indicated that TRAPPC9 was extensively expressed in the majority of tumor tissues, particularly in breast and colon cancer. More specifically, TRAPPC9 appeared to promote tumorigenesis via $\mathrm{NF}-\kappa \mathrm{B}$ signaling in breast MDA-MB-231 and colon HCT116 cancer cells. The downregulation of TRAPPC9 significantly inhibited the growth/proliferation, invasion/migration, colony formation and xenograft tumorigenesis of the breast and colon cancers cells (39).

\section{Concluding remarks}

TRAPPC9 is a conserved protein. The protein has been found to be expressed in different human tissues and is implicated 
Table II. Summary of human mutations associated with TRAPPC9.

\begin{tabular}{llll}
\hline Author, year $\quad$ Designation & Genotype & Phenotype
\end{tabular}

Mochida et al,2009 TRAPPC9 Nonsense nucleotide mutation. Defects in axonal connectivity. Variable postnatal microcephaly of a consanguineous Israeli Arab family.

Abbasi et al,2017 TRAPPC9 Homozygous nonsense mutation

Severe intellectual disability, motor delay, and c. $2065 \mathrm{G}>\mathrm{T}$ in exon 11 of the TRAPPC9 gene.

Marangi et al,2013 TRAPPC9 Homozygous splice sit mutation causing exon skipping with and premature termination. absent speech. frameshift

Peculiar facial appearance, obesity, hypotonia,

Philippe et al,2009 TRAPPC9 Nonsense mutation (c.1708C $>$ T[p.R570X]) within moderate-to-severe intellectual disability, and brain abnormalities. Identified in two Italian sisters born to healthy and apparently nonconsanguineous parents.

Mild microcephaly and white matter exon 9 .

TRAPPC9, trafficking protein particle complex 9.

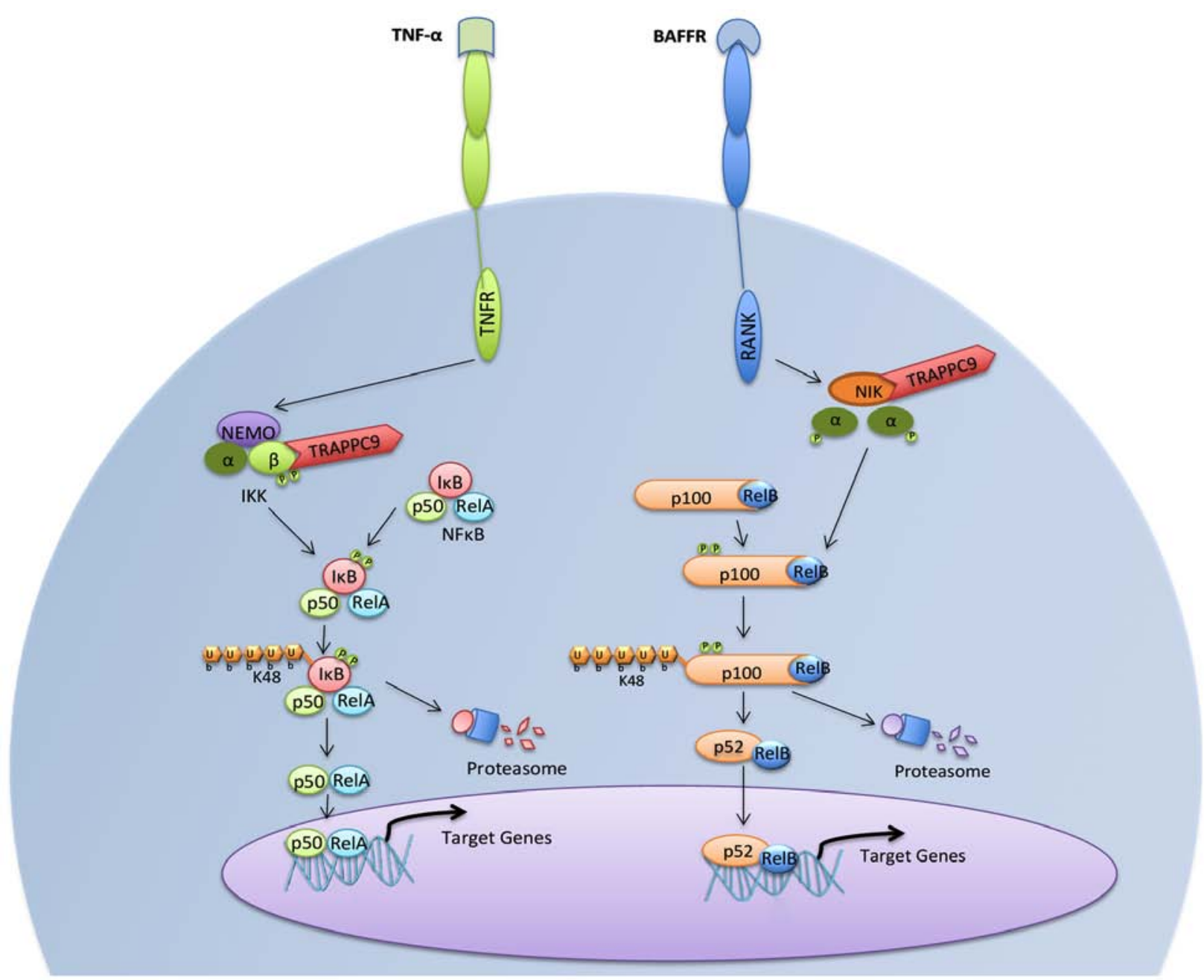

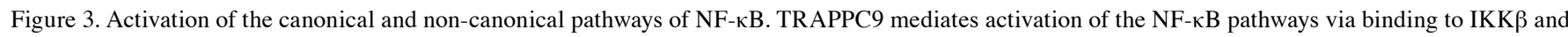
NIK. Canonical and non-canonical NF- $\mathrm{KB}$ pathway activation induces transcription factors that are involved in various biological processes, including the immune response, inflammation, cell growth and survival, and development. TRAPPC9, trafficking protein particle complex 9; NF- $\mathrm{kB}$, nuclear factor- $\mathrm{kB}$;

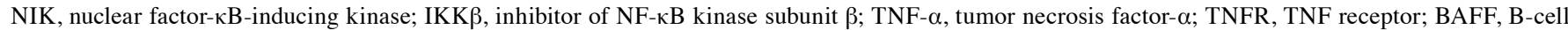
activating factor; BAFFR; BAFF receptor; NEMO, NF- $\kappa$ B essential modulator. 
in several intracellular protein trafficking processes. In addition, TRAPPC9 has been observed to be important in $\mathrm{NF}-\mathrm{\kappa B}$ signaling by directly binding and regulating NIK and IKK $\beta$; via these interactions, TRAPPC9 has been implicated in the canonical and non-canonical NF- $\kappa \mathrm{B}$ activation pathways. TRAPPC9 mutation may also be essential in the pathogenesis of a number of human diseases. Collectively these data highlight the importance of understanding the normal physiological roles of TRAPPC9 in NF- $\mathrm{BB}$-mediated signaling and in trafficking, as this can assist in improving our understanding of the role of TRAPPC9 in different disease processes.

\section{Acknowledgements}

The authors would like to thank the School of Biomedical Sciences, Kent State University for their support.

\section{Funding}

The present study was supported by the Cook Philanthropy Foundation (grant no., 72264).

\section{Availability of data and materials}

Data sharing is not applicable to this article, as no datasets were generated or analyzed during the current study.

\section{Authors' contributions}

TM and NJH contributed equally to manuscript writing and editing. AN assisted with preparing the figures. FFS contributed to the manuscript editing and writing. All authors read and approved the final manuscript for publication.

\section{Ethics approval and consent to participate}

No applicable.

\section{Patient consent for publication}

Not applicable.

\section{Competing interests}

The authors declare that they have no competing interests.

\section{References}

1. Kim JJ, Lipatova $Z$ and Segev N: TRAPP complexes in secretion and autophagy. Front Cell Dev Biol 4: 20, 2016.

2. Yip CK, Berscheminski J and Walz T: Molecular architecture of the TRAPPII complex and implications for vesicle tethering. Nat Struct Mol Biol 17: 1298-1304, 2010.

3. Zong M, Satoh A, Yu MK, Siu KY, Ng WY, Chan HC, Tanner JA and Yu S: TRAPPC9 mediates the interaction between $\mathrm{p} 150$ and COPII vesicles at the target membrane. PLoS One 7: e29995, 2012.

4. Mohamoud HS, Ahmed S, Jelani M, Alrayes N, Childs K, Vadgama N, Almramhi MM, Al-Aama JY, Goodbourn S and Nasir J: A missense mutation in TRAPPC6A leads to build-up of the protein, in patients with a neurodevelopmental syndrome and dysmorphic features. Sci Rep 8: 2053, 2018.
5. Mir A, Kaufman L, Noor A, Motazacker MM, Jamil T, Azam M, Kahrizi K, Rafiq MA, Weksberg R, Nasr T, et al: Identification of mutations in TRAPPC9, which encodes the NIK- and IKK-beta-binding protein, in nonsyndromic autosomal-recessive mental retardation. Am J Hum Genet 85: 909-915, 2009.

6. Schou KB, Morthorst SK, Christensen ST and Pedersen LB: Identification of conserved, centrosome-targeting ASH domains in TRAPPII complex subunits and TRAPPC8. Cilia 3: 6, 2014.

7. Zeytuni $\mathrm{N}$ and Zarivach R: Structural and functional discussion of the tetra-trico-peptide repeat, a protein interaction module. Structure 20: 397-405, 2012.

8. Clairfeuille T, Norwood SJ, Qi X, Teasdale RD and Collins BM: Structure and membrane binding properties of the endosomal tetratricopeptide repeat (TPR) domain-containing sorting nexins SNX20 and SNX21. J Biol Chem 290: 14504-14517, 2015.

9. Hwang JY, Ahn SJ, Kwon MG, Seo JS, Hwang SD and Son MH: Interferon-induced protein 56 (IFI56) is induced by VHSV infection but not by bacterial infection in olive flounder (paralichthys olivaceus). Fish Shellfish Immunol 66: 382-389, 2017.

10. Ponting CP: A novel domain suggests a ciliary function for ASPM, a brain size determining gene. Bioinformatics 22: 1031-1035, 2006.

11. Zhang Y, Bitner D, Pontes Filho AA, Li F, Liu S, Wang H, Yang F Adhikari S, Gordon J, Srinivasan S and $\mathrm{Hu} \mathrm{W}$ : Expression and function of NIK- and IKK2-binding protein (NIBP) in mouse enteric nervous system. Neurogastroenterol Motil 26: 77-97, 2014.

12. Sacher M, Barrowman J, Schieltz D, Yates JR III and Ferro-Novick S: Identification and characterization of five new subunits of TRAPP. Eur J Cell Biol 79: 71-80, 2000.

13. Mochida GH, Mahajnah M, Hill AD, Basel-Vanagaite L, Gleason D, Hill RS, Bodell A, Crosier M, Straussberg R and Walsh CA: A truncating mutation of TRAPPC9 is associated with autosomal-recessive intellectual disability and postnatal microcephaly. Am J Hum Genet 85: 897-902, 2009.

14. Sacher M, Jiang Y, Barrowman J, Scarpa A, Burston J, Zhang L, Schieltz D, Yates JR III, Abeliovich H and Ferro-Novick S: TRAPP, a highly conserved novel complex on the cis-Golgi that mediates vesicle docking and fusion. EMBO J 17: 2494-2503, 1998.

15. Cai H, Zhang Y, Pypaert M, Walker L and Ferro-Novick S: Mutants in trs120 disrupt traffic from the early endosome to the late golgi. J Cell Biol 171: 823-833, 2005.

16. Barrowman J, Sacher M and Ferro-Novick S: TRAPP stably associates with the golgi and is required for vesicle docking. EMBO J 19: 862-869, 2000.

17. Zahoor MA, Yamane D, Mohamed YM, Suda Y, Kobayashi K, Kato K, Tohya $\mathrm{Y}$ and Akashi $\mathrm{H}$ : Bovine viral diarrhea virus non-structural protein $5 \mathrm{~A}$ interacts with NIK- and IKKbeta-binding protein. J Gen Virol 91: 1939-1948, 2010.

18. Yu S and Liang Y: A trapper keeper for TRAPP, its structures and functions. Cell Mol Life Sci 69: 3933-3944, 2012.

19. Sacher M, Barrowman J, Wang W, Horecka J, Zhang Y,Pypaert M and Ferro-Novick S: TRAPP I implicated in the specificity of tethering in ER-to-golgi transport. Mol Cell 7: 433-442, 2001.

20. Choi C, Davey M, Schluter C, Pandher P, Fang Y, Foster LJ and Conibear E: Organization and assembly of the TRAPPII complex. Traffic 12: 715-725, 2011.

21. Hu WH, Pendergast JS, Mo XM, Brambilla R, Bracchi-Ricard V, Li F, Walters WM, Blits B, He L, Schaal SM and Bethea JR: NIBP, a novel NIK and IKK(beta)-binding protein that enhances NF-(kappa)B activation. J Biol Chem 280: 29233-29241, 2005.

22. Barrowman J, Bhandari D, Reinisch K and Ferro-Novick S: TRAPP complexes in membrane traffic: Convergence through a common rab. Nat Rev Mol Cell Biol 11: 759-763, 2010.

23. Delic M, Valli M, Graf AB, Pfeffer M, Mattanovich D and Gasser B: The secretory pathway: Exploring yeast diversity. FEMS Microbiol Rev 37: 872-914, 2013.

24. Zou S, Chen Y, Liu Y, Segev N, Yu S, Liu Y, Min G, Ye M, Zeng Y, Zhu X, et al: Trs130 participates in autophagy through GTPases Ypt31/32 in saccharomyces cerevisiae. Traffic 14: 233-246, 2013.

25. Montpetit B and Conibear E: Identification of the novel TRAPP associated protein Tca17. Traffic 10: 713-723, 2009.

26. Scrivens PJ, Shahrzad N, Moores A, Morin A, Brunet S and Sacher M: TRAPPC2L is a novel, highly conserved TRAPP-interacting protein. Traffic 10: 724-736, 2009.

27. Yamasaki A, Menon S, Yu S, Barrowman J, Meerloo T, Oorschot V, Klumperman J, Satoh A and Ferro-Novick S: mTrs130 is a component of a mammalian TRAPPII complex, a Rab1 GEF that binds to COPI-coated vesicles. Mol Biol Cell 20: 4205-4215, 2009. 
28. Israel LP, Benharoch D, Gopas J and Goldbart AD: A pro-inflammatory role for nuclear factor kappa B in childhood obstructive sleep apnea syndrome. Sleep 36: 1947-1955, 2013.

29. Brasier AR: The NF-kappaB regulatory network. Cardiovasc Toxicol 6: 111-130, 2006.

30. Hayden MS and Ghosh S: Shared principles in NF-kappaB signaling. Cell 132: 344-362, 2008.

31. Sun SC: The noncanonical NF- $\kappa B$ pathway. Immunol Rev 246: 125-140, 2012.

32. Sun SC: Non-canonical NF-kappaB signaling pathway. Cell Res 21: 71-85, 2011

33. Abbasi AA, Blaesius K, Hu H, Latif Z, Picker-Minh S, Khan MN Farooq S, Khan MA and Kaindl AM: Identification of a novel homozygous TRAPPC9 gene mutation causing non-syndromic intellectual disability, speech disorder, and secondary microcephaly. Am J Med Genet B Neuropsychiatr Genet 174: 839-845, 2017.

34. Najmabadi H, Motazacker MM, Garshasbi M, Kahrizi K, Tzschach A, Chen W, Behjati F, Hadavi V, Nieh SE, Abedini SS et al: Homozygosity mapping in consanguineous families reveals extreme heterogeneity of non-syndromic autosomal recessive mental retardation and identifies 8 novel gene loci. Hum Genet 121: 43-48, 2007.

35. Philippe O, Rio M, Carioux A, Plaza JM, Guigue P, Molinari F, Boddaert N, Bole-Feysot C, Nitschke P, Smahi A, et al Combination of linkage mapping and microarray-expression analysis identifies NF-kappaB signaling defect as a cause of autosomal-recessive mental retardation. Am J Hum Genet 85 : 903-908, 2009.
36. Kakar N, Goebel I, Daud S, Nürnberg G, Agha N, Ahmad A, Nürnberg P, Kubisch C, Ahmad J and Borck G: A homozygous splice site mutation in TRAPPC9 causes intellectual disability and microcephaly. Eur J Med Genet 55: 727-731, 2012.

37. Marangi G, Leuzzi V, Manti F, Lattante S, Orteschi D, Pecile V, Neri G and Zollino M: TRAPPC9-related autosomal recessive intellectual disability: Report of a new mutation and clinical phenotype. Eur J Hum Genet 21: 229-232, 2013.

38. Wattacheril J, Lavine JE, Chalasani NP, Guo X, Kwon S, Schwimmer J, Molleston JP, Loomba R, Brunt EM, Chen YI, et al: Genome-wide associations related to hepatic histology in nonalcoholic fatty liver disease in hispanic boys. J Pediatr 190: 100-107.e102, 2017.

39. Zhang Y, Liu S, Wang H, Yang W, Li F, Yang F, Yu D, Ramsey FV, Tuszyski GP and Hu W: Elevated NIBP/TRAPPC9 mediates tumorigenesis of cancer cells through $\mathrm{NF \kappa B}$ signaling. Oncotarget 6: 6160-6178, 2015.

40. Li C, Luo X, Zhao S, Siu GK, Liang Y, Chan HC, Satoh A and Yu SS: COPI-TRAPPII activates Rab18 and regulates its lipid droplet association. EMBO J 36: 441-457, 2017.

41. Salamat MK, Dron M, Chapuis J, Langevin C and Laude $\mathrm{H}$ : Prion propagation in cells expressing $\mathrm{PrP}$ glycosylation mutants. J Virol 85: 3077-3085, 2011.

42. Thellmann M, Rybak K, Thiele K, Wanner G and Assaad FF: Tethering factors required for cytokinesis in arabidopsis. Plant Physiol 154: 720-732, 2010. 